\title{
Virtual Methods: issues in social research on the Internet
}

\author{
Christine Hine (Ed.) \\ Berg Publishers \\ Oxford \\ 2005 \\ 242 pages \\ ISBN 1-84520-085-3 \\ $£ 16.99$ (Paperback)
}

\author{
George Macgregor \\ Centre for Digital Library Research \\ Department of Computer \& Information Science \\ University of Strathclyde, UK
}

For library and information science, the advent of the web continues to challenge our understanding of the profession and the services we provide to users. Meeting this challenge is by no means a simple process, but some might say that we are aided in our efforts by virtue of the fact that, as a profession, we have promulgated many of the said developments ourselves. Some might also say that we are aided in our efforts by the relatively linear nature of our discipline. There are many research questions within LIS which are conducive to quantitative analyses and robust qualitative explorations; sociological and anthropological questions relating to LIS account for a minority of research, for example.

The situation is quite different for those in the social sciences and humanities. Here, the web has given rise to a plethora of new social formations. Individuals and societies communicate and organise themselves via web sites, social software, email, mobile communication technologies, and other forms of Computer-Mediated Communication (CMC). CMC has become such a significant component of normal social life that it is imperative social researchers research, interpret and understand these rich interactions and the social questions they expose. Yet, analyses of such phenomena by social researchers are fraught with difficulty and apprehension. Capturing robust data remains difficult and it is unclear how applicable previous methodological frameworks are within these virtual contexts.

Virtual Methods aims to resolve this anomaly. Edited by Christine Hine (Department of Sociology, University of Surrey, UK), Virtual Methods is a collection of papers culled from a series of related seminars and is essentially an 'exploration' of the various difficulties, complexities, and opportunities of social research within the $\mathrm{CMC}$ environment. Hine frames the book with a useful introductory chapter outlining the problems faced by social researchers. Says Hine: "Methodological solutions gain much of their authority through precedent, and it is not clear as yet just how far the heritage of research methodology applies to new media and what gaps in our understanding are still to be exposed" (p.1). Virtual Methods provides such a precedent, containing 14 case studies and reviews detailing methodological approaches to capturing and interpreting social interactions mediated by ICT. Perhaps more interestingly, these contributions emanate from wildly disparate disciplines, spanning sociology, anthropology, geography, media studies, information science, and so forth.

The book is divided into two parts: research relationships and online relationships, and; research sites and strategies.

The issue pervading most of the first part of Virtual Methods is trust. Replicating in a virtual context the trust afforded between researcher and subject in, say, a face-to-face interview is problematic; the researcher and subject are bereft of visual cues and trust has to be built purely within anonymous, ethereal, textual settings. Several authors take trust issues head on by wrestling with online interviewing techniques. For example, Shani Orgad (Department of Media and Communications, London School of Economics and Political Science) discusses her use of online interviewing in tandem with more established methods while investigating the role played by the Internet in the lives of breast cancer patients. Her use of multiple methods enables a 'triangulation of methods' and an increase in the validity of results gleaned; however, it leads Orgad to confront complex ethical concerns. Increased depersonalisation eventually manifests itself in extremely frank and personal correspondence with study participants, many of whom consider Orgad as a friend or confidant. Since long-term online trust is a prerequisite to moving relationships from the online environment to the offline environment, Orgad provides constructive guidance on how to juggle scientific rigour with the complex ethical issues that 
often typify social research. It is perhaps noteworthy, however, that only one author (Joëlle Kivits, London School of Economics) documents the use of online interviewing as the exclusive weapon of choice. Most researchers use online interviewing (or other instruments) as a complement to conventional 'real life' methodologies, perhaps signifying that virtual methods have yet to mature sufficiently so as to enable a species of social research completely autonomous from bona fide social interaction.

Part two attempts to grapple with some of issues expounded in part one, and in particular those pertaining to research site definition. The use of technology to facilitate visualisations of social formations and interactions is also explored. For example, in his paper, 'The role of maps in virtual research methods', Martin Dodge (Department of Geography, University College London) illustrates how maps can be utilised to observe complex social relationships more easily, thus allowing a clearer understanding of social phenomena, the identification of interactions or relationships that might otherwise have been neglected, and the conception of new and innovative hypotheses to be tested.

Arguably the most interesting contribution in part two comes from Schneider and Foot (SUNY Institute of Technology, New York and University of Washington), who ponder the challenges in defining research sites and propose a 'web sphere' as a convenient unit of analysis. This unit comprises a "set of dynamically defined digital resources spanning multiple websites deemed relevant or related to a central event, concept or theme, and often connected by hyperlinks. The boundaries of a web sphere are delimited by a shared topical orientation and a temporal framework" (p.158). Despite being a convenient unit of analysis, controlling and managing a web sphere for research purposes is unsurprisingly difficult. Perhaps more surprisingly, Schneider and Foot prefer 'dynamic boundaries' since the researcher can act upon unanticipated developments and emergent web sphere trends. Even in predictable web spheres that contain predictable actors, unexpected events can occur ('web storms', such as 11 September), leading to the production of numerous textual, interlinked web documents in a short space of time. Unless the social researcher is responsive to such web storms, they run the risk of missing rich sources of data pertaining to online action and social behaviour.

Virtual Methods is a useful foray into the methodological hazards inherent in CMC research, and those intending to dip their toes in such scalding water would best be advised to dip their nose into Virtual Methods instead, at least in the first instance. A nice and varied collection of papers awaits the reader, each highlighting problems and opportunities, methodological conundrums and practical solutions. References from each of the papers are collated at the back, providing an exhaustive list of references to aid further reading for the novice researcher. If some criticism could be levelled it would be at the sheer fuzziness of some expositions. Some (particularly those in part two) teeter on the nebulous and would benefit from practical examples or sample datasets to appreciate how methodologies could best be deployed, and how data could be usefully captured. 